\title{
REPRESENTAÇÕES SOCIAIS DE CIÊNCIA E RELIGIÃO
}

\author{
Willian Oliveira Santos ${ }^{1}$, Kiara Tatianny Santos da Costa ${ }^{2}$, Nayara Tatianna \\ Santos da Costa ${ }^{2}$, Jair Stefanini Pereira de Ataíde ${ }^{2}$ \\ ${ }^{1}$ Mestrado em Física, Universidade Federal de Campina Grande, Campina Grande-PB, Brasil. \\ ${ }^{2}$ Professores Unidade Acadêmica de Física e Matemática, Universidade Federal de Campina \\ Grande, Cuité, PB, Brasil. \\ Email para correspondência: kiara.tatianny@professor.ufcg.edu.br
}

\begin{abstract}
Resumo
O objetivo deste trabalho foi analisar as representações sociais de Ciência e Religião. Apreender as representações sociais possibilita compreender a possibilidade de ensinar Ciências em uma sociedade em que predomina uma cultura religiosa. Nosso referencial teórico e metodológico utilizado foi a Teoria das Representações Sociais via abordagem estrutural de ABRIC. Como instrumento de coleta de dados foi utilizado o Teste de Associação Livre de Palavras (TALP) aplicado com 70 participantes. Nesse trabalho trazemos a análise das respostas dos participantes por meio da justificativa dada para a associação livre realizada. Utilizamos as justificativas dos participantes que foram analisadas com base em Bardin via análise de conteúdo e integram a segunda parte do questionário aplicado durante a pesquisa. Os resultados demonstram que as Representações Sociais de ciência estão interligadas com as Representações construídas socialmente acerca da religião, ou seja, o pensamento construído sobre religião também tem interferência na construção da representação sobre ciência.
\end{abstract}

Palavras-chave: Representações sociais, Ciência, Religião.

\begin{abstract}
The objective of this work was to analyze the social representations of Science and Religion. Understanding the social representations makes it possible to understand the possibility of teaching Science in a society in which a religious culture predominates. Our theoretical and methodological framework used was the Theory of Social Representations via the structural approach of ABRIC. As a data collection instrument, the Free Word Association Test (TALP) was applied with 70 participants; 35 students from the 5 courses of the Education and Health Center of the Federal University of Campina Grande - UFCG, and 35 from the community in general. In this work, we bring the analysis of the participants' responses through the justification given for the free association carried out by the participants. We used the participants' justifications that were analyzed based on Bardin via content analysis and are part of the second part of the questionnaire applied during the research. The results show that the Social Representations of science are very interconnected with
\end{abstract}


the Socially Constructed Representations about religion, that is, the thought built on religion also interferes in the construction of the representation about science.

Keywords: Social Representation, Science; Religion.

\section{Introdução}

Segundo Paiva (2002) Ciência e Religião têm sido um binômio problemático em algumas áreas da cultura ocidental, entretanto, apesar de suas molduras distintas, com convergências e discrepâncias, procura-se por meio de interesse acadêmico uma forma de articulá-las. Salienta-se, portanto, a necessidade de ampliar o espaço de debate no campo das representações sociais de ciência e religião, visto que cada uma dessas áreas, com suas particularidades orienta a forma de pensar e fazer dos indivíduos em seu cotidiano.

Para Souza e colaboradores (2004), ciência e religião vêm mostrando um mútuo interesse de aproximação. São muitos os que se veem nesta articulação um resultado proveitoso atualmente, desde antes muitos estudiosos contribuíam para um bom relacionamento dessas duas áreas, a exemplo de Einstein, como ressalta Souza e colaboradores (2004). A partir de Einstein reduziram-se, um a um, os impedimentos de cercania para ciência e religião, a ponto de o próprio João Paulo II afirmar que religião sem ciência não é boa religião, bem como ciência sem religião não é boa ciência, daquilo que o pensamento religioso guardava de dogmatismo, para poder constituir-se como domínio disciplinar, dentro de um outro paradigma. (SOUZA et.al. 2004). Acredita-se que a relação entre essas duas áreas possa crescer cada vez mais. Pois, permite uma interligação maior entre as pessoas e com o mundo a sua volta, atuando assim de forma interdisciplinar no processo de ensino e aprendizagem.

De acordo com Jupiassu (2006), o caráter interdisciplinar não só promove a união do ensino e da pesquisa, como também transforma as escolas de um simples lugar de transmissão de conhecimentos pré-estabelecidos em um lugar onde se produz criticamente e coletivamente, bem como na construção de uma nova relação entre educadores e educandos. Apesar do interesse de articulação ou forma de lidar com estas áreas distintas, não tem sido fácil para os profissionais de educação colocar em prática essa articulação entre ciência e religião. Vivemos rodeados de diversos tipos de religiões e crenças distintas que fazem parte do cotidiano dos alunos e consequentemente de suas culturas. Destacamos as mais fortes religiões que predominam no Brasil e encontramos o Cristianismo como 
sendo a predominante, sendo ela também presente no dia a dia da sociedade, que se estabelece por meio da crença e da fé em um Deus que criou todas as coisas.

No cristianismo encontramos o catolicismo que há centenas de anos encontra seu espaço na vida das pessoas por meio de seus ritos culturais. Além deste, destacamos no Cristianismo, o meio Evangélico que vem crescendo consideravelmente nos últimos 100 anos no Brasil e que de acordo com Dorvillé e Selles (2016), sua influência crescente tem implantado desafios, também, para os professores da área de ciências e biologia, uma vez que a teoria evolutiva vai de encontro às interpretações criacionistas da origem da vida.

Em contrapartida com a religião que se firma por meio da fé, a Ciência está estabelecida por meio do processo de investigação, experimentação e pesquisa. Por isso a grande dificuldade no meio educacional e a preocupação por parte dos profissionais de ensino crescem a cada dia. Nosso questionamento se centra em como estabelecer estratégias para não ferir os princípios éticos da humanidade, sem deixar com que o processo de ensino de ciências seja negligente.

Um ponto de motivação principal para realização desta pesquisa, foi ter encontrado divergências entre as ideias científicas e religiosas no pensar do ensino de Ciências. Para tentar entender essas questões e dificuldades na prática docente, usamos a Teoria das Representações Sociais como fundamento teórico e metodológico que orientam as reflexões de tais questões. Desta forma, este trabalho traz como objetivo central analisar as representações sociais de ciência e religião. Este trabalho integra uma pesquisa mais ampla que foi desenvolvida na Licenciatura em Física na Universidade Federal de Campina Grande, Campus de Cuité - Paraíba.

A Teoria das Representações Sociais (TRS) teve seu início na Europa expressivamente na França. O pioneiro da TRS foi Sérge Moscovici com o propósito de resolver as problemáticas encontradas nos conceitos da psicologia social, partindo da ideia de que existem modelos diferentes de conhecer e de se comunicar. Em seu estudo, La Psycanalyse: son image et son public, publicada em 1961, Moscovici (1961), analisou a interação social dos indivíduos (SANTOS e ALMEIDA; 2005; DOS SANTOS e DIAS 2015). 
As bases teóricas para TRS são abordadas de três maneiras, a primeira regulada nos estudos de Jodelet (2001) é caracterizada por uma metodologia de pesquisa centrada na análise do discurso dos sujeitos, representantes do grupo em que se originam as representações sociais investigadas, a segunda organizada nos argumentos de Doise, que é identificada através do interesse pelas condições sociais que produzem e fazem circular as representações sociais, terceira fluente por Abric (2003, p.38) dá ênfase ao caráter estrutural e cognitivo, organizado nas opiniões, nas atitudes, crenças e de informações referentes a um objeto central (DOS SANTOS e DIAS, 2015; SILVA, 2014; ATAÍDE e FREIRE; 2011; SANTOS e ALMEIDA; 2005).

A Teoria do Núcleo Central (TNC) surgiu no estudo de Abric (2000), defendendo a hipótese que toda representação seria constituída em torno de um núcleo central estruturado, definindo uma coexistência de duas lógicas distintas a cognição e o social. O Núcleo Central (NC) e as zonas periféricas, são os termos que estruturam a Teoria do Núcleo Central (TNC) para compreensão cognitiva das representações sociais. Núcleo Central (NC) determina a organização e significação, enquanto os elementos periféricos são diversificados e flexíveis.

Observamos no quadro abaixo as características e as funções diferenciadas dos dois sistemas para organização da TRS (ATAÍDE, 2011; SÁ, 1996).

Quadro 1 - Organização interna das TRS, diferentes instâncias estruturais Sistema Central Sistema Periférico

\begin{tabular}{|c|c|}
\hline \multicolumn{2}{|c|}{ Sistema Central } \\
\hline $\begin{array}{c}\text { Ligado à memória e à história do grupo } \\
\text { Consensual; define a homogeneidade do } \\
\text { grupo }\end{array}$ & $\begin{array}{c}\text { Sermite a integração das experiências e } \\
\text { da história individual }\end{array}$ \\
\hline Estável & Flexível \\
\hline Resistente à mudança & Evolutivo heterogeneidade do grupo \\
\hline Pouco sensível ao contexto & Sensível ao contexto \\
\hline
\end{tabular}

O núcleo central é a principal parte de uma representação e uma alteração dessa estrutura pode modificar uma representação social; já o sistema periférico, como anteriormente mencionado, é um sistema mais flexível, funcionando como 
guarda-chuva do sistema central da representação. Este sistema é mais acessível e, portanto, serve como proteção ao núcleo central. As mudanças no sistema periférico podem ocorrer sem necessariamente significar uma mudança na representação social de cada indivíduo, visto que nem sempre as mudanças que atingem o sistema periférico atingem também o sistema central. Para que 0 sistema central possa ser modificado, deve haver uma interferência que conflite com a existência deste, ou seja, o sistema central deve ser posto em conflito com outras representações que o questionem. Dessa forma, Abric (2000) indica que para se aproximar de uma representação social é preciso identificar a estrutura e o conteúdo destas representações.

\section{Percurso metodológico}

O estudo realizado se caracteriza como abordagem quanti qualitativa que se fundamenta na TRS via abordagem estrutural de Abric (2000). Para esta teoria, a representação social está estruturada a partir de dois núcleos, o central e o periférico. Abric (1994) também indica uma estrutura metodológica de trabalho no campo indicado. Para acessar o conteúdo e a estrutura de uma representação, esse autor propõe técnicas associativas e interrogativas de investigação. Foi utilizado nesse estudo, a técnica associativa (TALP - Teste de Associação Livre de Palavras). Essa técnica era composta de duas partes. Na primeira, foi feito o levantamento do conteúdo e da estrutura da representação, na qual a partir dos termos indutores " $1^{\circ}$ - Para você Religião é... e 2ํㅡ - Para você Ciência é..." foi solicitado que os participantes indicassem 4 palavras que lhe vinham a mente ao ler as expressões indicadas acima.

Após esta etapa, era solicitado que ordenassem as palavras de acordo com sua importância, o que dava a possibilidade de refletir mais uma vez sobre 0 significado do termo apresentado, por fim, solicitou-se que justificassem a escolha da primeira palavra indicada como mais importante para explicar o significado do termo indutor. É essa última etapa trazemos para análise neste artigo.

Participaram os estudantes dos cursos de Licenciatura em Matemática, Física, Química e Biologia do Centro de Educação e Saude - CES da Universidade Federal de Campina Grande - UFCG; e também cidadãos das comunidades 
circunvizinhas da universidade: Nova Palmeira, Picuí, Frei Martinho, Nova Floresta e Cuité.

Foram distribuídos e respondidos entre os estudantes um total de trinta e cinco (35) questionários, no qual foram subdivididos em todos os cursos do CES/UFCG e trinta e cincos (35) Cidadãos das comunidades circunvizinhas, sendo: (5) cinco em Nova Palmeira; cinco (5) Picuí, cinco (5) Frei Martinho; sete (7) Nova Floresta e onze (11) Cuité, e outros dois (2) na comunidade Quilombola Serra do Abreu localizada entre Picuí e Nova Palmeira, totalizando setenta (70) a quantidade geral de questionários aplicados.

$\mathrm{Na}$ análise dos dados foi utilizado o software Evocações, produto desenvolvido por Ataíde e Freire (2011) na dissertação de mestrado em Ensino de Ciências e Educação Matemática da Universidade Estadual da Paraíba, o algoritmo disponibiliza a opção de número de evocações que podem ser inseridas, obtidas dos termos ou frases estímulos que se propôs a pesquisa, o qual pode ser três, quatro ou cinco evocações (nessa pesquisa, utilizamos quatro evocações como dito anteriormente). Com relação aos dados qualitativos estabelecemos após o procedimento indicado por Bardin (2011) leitura flutuante, pré análise e análise categorial temática; categorias temáticas previamente pensadas a partir da literatura estudada e reformulada com base na análise das respostas dadas quando da justificativa no questionário.

\section{O núcleo central das Representações Sociais de Ciência e Religião: análise dos resultados}

$\mathrm{Na}$ primeira etapa desse estudo conseguimos identificar o conteúdo e a estrutura das representações sociais de ciência e religião. Nosso objetivo aqui é apenas analisar as justificativas dos participantes para testagem do núcleo central dessas representações. Dessa forma, apresentamos neste espaço o que encontramos na primeira etapa ${ }^{1}$ de análise a título de compreensão para a etapa seguinte.

\footnotetext{
1 Para uma leitura completa de todo processo de pesquisa ler o Trabalho de monografia intitulado "Representações sociais de Ciência e Religião" de Willian Oliveira Santos disponível na biblioteca do CES - UFCG.
} 
Ao analisar o primeiro termo indutor: "Para você Religião é..." Obteve-se um total de 404 palavras no qual, ao desprezar as evocações cuja frequência foi igual a 1, obteve-se 160 palavras, sendo 40 diferentes (que também se denomina de categorias na classificação dos elementos). A partir desses dados obtém-se: o número de vezes que a categoria foi evocada (S EVOC), a ordem média de evocação (OME) para cada categoria, média das ordens médias de evocação (MOME), cujo valor foi aproximadamente igual a 2,65 e a frequência média de evocação (f) com o valor por volta de 2,66. Católico 51\% Evangélico, 27\% Sem Religião 16\% Agnóstico 6\% Religião Para determinação do núcleo central e sistema periférico, foram consideradas a frequência das categorias evocadas e a ordem média de evocação de ocorrência das categorias produzidas. A frequência diz respeito ao número de vezes que a palavra foi evocada, e a ordem média de evocação refere-se à ordem de evocação estabelecida pelos participantes no processo cognitivo de hierarquização.

Para melhor compreensão apresentamos os elementos encontrados como possíveis integrantes do núcleo central das representações sociais para cada termo indutor apresentado.

Quadro 1: Elementos centrais aos termos indutores aplicados na pesquisa

\begin{tabular}{|c|c|}
\hline "Para você Religião é..." & "Para você Ciência é..." \\
\hline Elementos Centrais & Elementos Centrais \\
\hline OME $\leq 2,650321$ e f $\geq 2,666667$ & OME $\leq 2,710932$ e f $\geq 2,857143$ \\
\hline DECISÃO & EXPERIMENTO \\
\hline AMOR & CERTEZA \\
\hline CAMINHO & CONHECIMENTO \\
\hline FÉ & PESQUISA \\
\hline DEUS & SOLUÇÃO \\
\hline ESCOLHA & VIDA \\
\hline CRENÇA & DESCOBERTA \\
\hline CONHECIMENTO & RAZÃO \\
\hline RESPEITAR & TECNOLOGIA \\
\hline IMPORTANTE & EVOLUÇÃO \\
\hline \multirow[t]{5}{*}{ OBEDIÊNCIA } & ESTUDO \\
\hline & SABEDORIA \\
\hline & COMPROVAÇÃO \\
\hline & NECESSÁRIA \\
\hline & FUTURO \\
\hline
\end{tabular}

Fonte: produção da pesquisa 
Para ser considerado como elemento central da representação social as palavras precisam indicar a posição superior esquerda no quadrante de quatro casas que é estruturado pelo resultado obtido pelo tratamento dos dados no software Evocações, na qual a ordem média de evocação se associa também a indicação de tal palavra como mais importante. Diante disso, as palavras que se colocaram como indicadas a representar o significado da representação associada a Religião e Ciência são apresentadas no quadro acima. Para testagem do núcleo central recorremos então a hierarquização de importância das palavras e as justificativas que abaixo são apresentadas e analisadas.

Ao relacionar as palavras indicadas ao núcleo central nas representações sociais dos participantes da pesquisa, é possível perceber contradições entre os significados de ciência e religião, mas também é possível verificar que há palavras que se encontram com sentidos próximos, porém com enfoques diferentes.

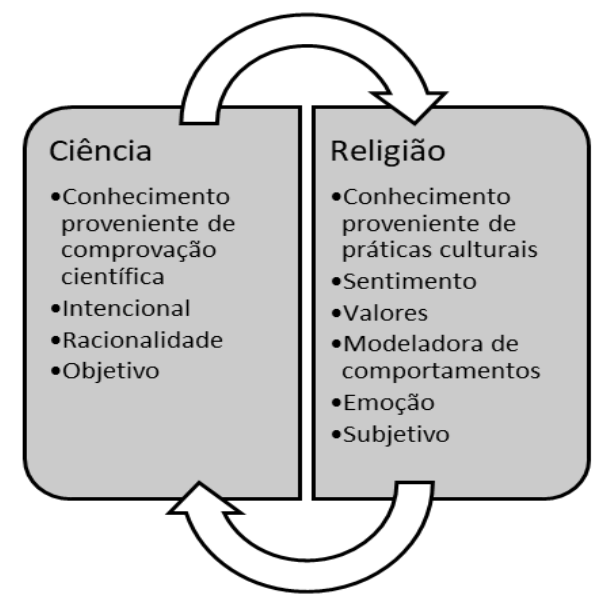

Figura 1: Categorias temáticas encontradas nas justificativas dos Participantes Fonte: produção da pesquisa

É possível ver na figura acima as categorias temáticas encontradas nas falas dos participantes. Encontramos palavras iguais que expressam sentidos diferentes, podemos perceber que a palavra conhecimento foi identificada para dois termos indutores, mas sua elocução traz sentidos diferentes. Para Ciência, conhecimento é proveniente de comprovação científica e para Religião, conhecimento proveniente de práticas culturais, bem como foram encontradas também oposições claras que caracterizam ciência e religião. As características foram indicadas a partir da análise do conteúdo das representações sociais das pessoas participantes da pesquisa, e configuram o sentido expresso por elas ao 
serem requeridas a pensar sobre o significado de ciência e religião. Analisemos as categorias a partir das palavras indicadas ao núcleo central.

Para ciência, objetividade, conhecimento proveniente de estudo que prescinde de comprovação. Para religião, por outro lado, apresenta-se a oposição de um conhecimento que tem suas raízes nos aspectos culturais de uma sociedade, que necessita de acreditar em algo que vai além da realidade tácita, visível e comprovada.
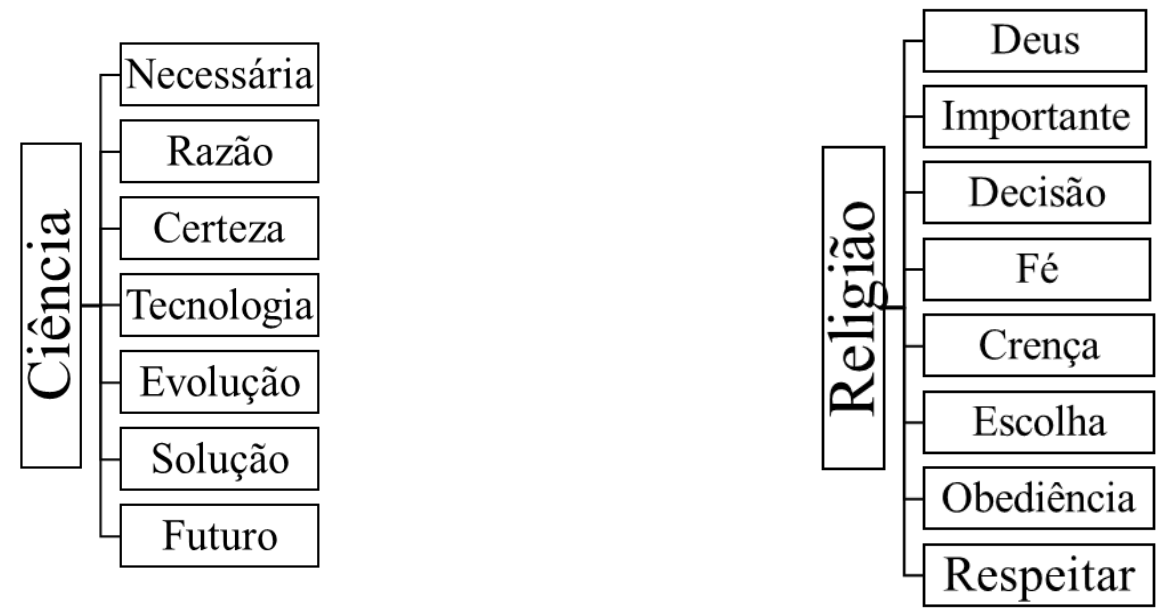

Figura 3: Diagrama do corpus das representações sociais sobre Ciência e Religião Fonte:produção da pesquisa

Também são expressos sentimentos que ressaltam a valoração de cada um. Para ciência, a importância se apresenta por ser algo necessário para o futuro da sociedade, da qual se permite inovar e avançar; para a religião essa importância é relacionada a uma doutrina de conformação dos comportamentos que orienta a vida em sociedade e da qual é preciso respeitar.

O lado afetivo também se apresenta nas representações das pessoas que responderam ao questionário. Esse lado afetivo se apresenta como um caminho repleto de amor no âmbito da religião, mas para a ciência é efetivamente a vida e a sua existência a ela relacionada, que pode-se inferir estar relacionada a aspectos mais relacionados ao organismo biológico e intelectual. 

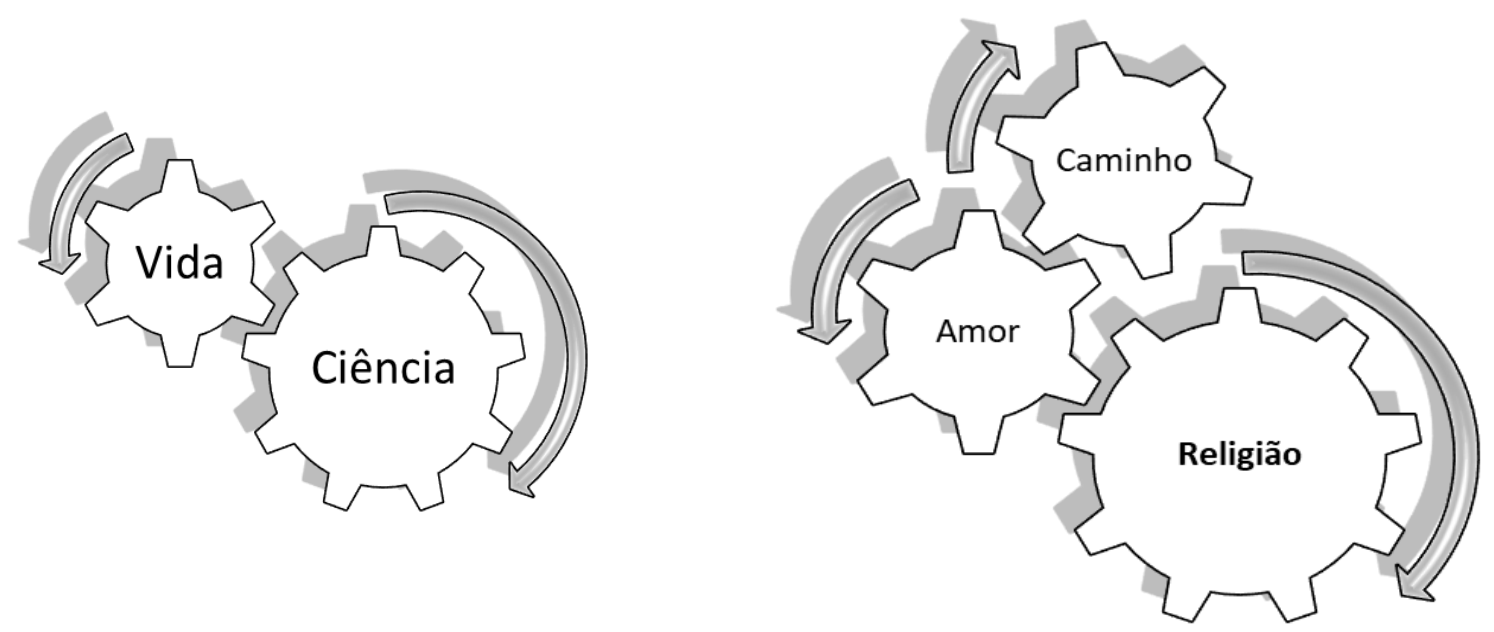

Figura 4: $O$ lado afetivo nas representações

Fonte: produção da pesquisa

No conteúdo das falas dos participantes verifica-se que a Religião se configura como um movimento de amar a Deus, nessa linha argumentativa, é oportuno observar que o amor tem sido o caminho mais importantes como compromisso da humanidade até o Ser superior, de modo análogo Ciência tem comportamento que se caracteriza o caráter ou a identidade de uma coletividade de convivência que norteia desde as mais simples ações até a mais complexa, ou seja, modo de viver; conjunto de hábitos, resumindo tudo na palavra vida. Desse modo, os resultados apresentados demonstram uma relação entre o pensamento construído sobre religião que também interfere na construção do pensar a ciência. Alguns momentos percebe-se aproximação, em outros uma contraposição destes. Porém vê-se que a partir de uma dimensão emocional, recorre-se a ciência para explicar a vida de forma mais objetiva, porém a aproximação com a religião fazse para dar sentido a esta. Sendo assim, ensinar ciências diante de tal contexto prescinde compreender esse movimento de aproximação e repulsa entre as duas temáticas que influenciam no pensar socialmente.

\section{Considerações finais}

O trabalho trouxe a trajetória de uma pesquisa que teve por objetivo analisar as representações sociais de ciência e religião. Notamos que os termos que foram evocados para definição de ciência e religião traz intrínsico os sentimentos que ressaltam a valoração de cada um. Para termo ciência, concluímos que o 
significado mais expressado para sociedade investigada traz o sentido de futuro, no qual chamamos atenção para os termos inovar e avançar; e para termo religião os sentimento de subjetividade, chamamos atenção para os termos Deus e fé.

Procuramos analisar com profundidade sentimento por traz de cada palavra evocada, para compreender a complexidade das relações que podem vir a estabelecer-se entre os conhecimentos religiosos e científico, mostrando como pode ser uma simplificação excessiva afirmar somente que ambas são incompatíveis ou compatíveis. Na verdade, para chegar-se a convicção desta natureza, é preciso ter uma série de fatores que parecem ser determinantes do tipo de relação que pode estabelecer-se entre conhecimento religioso e conhecimento científico.

\section{$5 \quad$ Referências}

ABRIC, J.-C. Méthodologie de recueil des représentations sociales. In: ABRIC, J.C. (Dir.) Pratiques Sociales et Representations. Paris: Presses Universitaires de France-PUF, 1994.

ABRIC, J-C. Abordagem estrutural das representações sociais: desenvolvimentos recentes. In: CAMPOS, Pedro H.F.; LOUREIRO, M. C. de S. (orgs.) Representações sociais e práticas educativas. Goiania, Ed. UCG, 2003. (série Didática).

ABRIC, J. C. A abordagem estrutural das Representações Sociais. In: MOREIRA, A. S. P. e OLIVEIRA, D. C (Orgs.). Estudos Interdisciplinares de Representação Social. Goiania AB, 2000.

ATAÍDE, J. S. P. As representações sociais dos estudantes de dois cursos de licenciatura em física da Paraíba. 152 f. Dissertações (Mestrado em Ensino de Física) - Universidade Estadual da Paraíba, Campina Grande, 2011.

BARDIN, Laurence. Análise de conteúdo. Lisboa, Edições 70, 2010

BORGES, Moema da Silva; SANTOS, Marília Borges Couto; PINHEIRO, Tiago Gomes. Representações sociais sobre religião e espiritualidade. Revista Brasileira de Enfermagem, v. 68, n. 4, p. 609-616, 2015.

DORVILLÉ, Luís Fernando Marques; SELLES Sandra Lúcia Escovedo. Criacionismo: transformações históricas e implicações para o ensino de Ciências e Biologia . Cadernos de Pesquisa, v.46, n.160, p.442-465 abr./jun. 2016.

JODELET, Denise. Representações Sociais: um domínio em expansão. In:

(Org.). As Representações Sociais. Tradução: Lilian Ulup. Rio de Janeiro, EdUERJ, 2001. p. 17-44. 
JUPIASSU, Hilton. O ESPÍRITO INTERDISCIPLINAR. Cadernos EBAPE.BR, V. IV, n. 3, Outubro 2006.

MOSCOVICI, S. La psychanalyse, son image et son public. Paris: PUF, 1961.

PAIVA, Geraldo José de. Ciência, Religião, Psicologia: Conhecimento e Comportamento. Psicologia: Reflexão e Crítica, 2002, 15(3), pp. 561-567

SÁ, Celso Pereira de. Núcleo central das representações sociais. Petrópolis,RJ: Vozes, 1996.

SANTOS, Geovane Tavares e DIAS, José Manuel de Barros. "Teoria das representações sociais: uma abordagem sociopsicológica." PRACS: Revista Eletrônica de Humanidades do Curso de Ciências Sociais da UNIFAP. 8, no. 1 (2015): 173-187.

SANTOS, Maria de Fátima de Souza, ALMEIDA, Leda Maria de. Diálogos com a teoria da representação social. Editora Universitária UFPE, 2005

SILVA, Karla Costa. "Representações sociais da Arquivologia e do arquivista: o caso do Campus $V$ da UEPB." Trabalho de Conclusão de Curso (Graduação em Arquivologia) - Universidade Estadual da Paraíba, João Pessoa, 2014.

SOUSA, Paulo L. R. LEDA A. TILLMANN, CRISTINA L. HORTA, FLÁVIO M. DE OLIVEIRA. Espiritualidade e Qualidade de Vida. A religiosidade e suas interfaces com a Medicina, a Psicologia e a Educação: o estado da arte. Porto alegre, 2004. 